\title{
Analysis of Proximate Composition and Functional Properties of Selected Edible Leaves: Nutritional and Therapeutic Implication
}

\author{
A. D. Pal*, T. M. Zakir \\ Department of Food Science \& Nutrition Management, J. D. Birla Institute, Kolkata-700020, India
}

Received 23 January 2020, accepted in final revised form 4 May 2020

\begin{abstract}
The present study was designed to document the nutritional and functional properties of Ceylon Spinach, Mustard as well as Pumpkin leaves. These samples were selected owing to their economic affordability and utilization within the local population. Proximate analysis revealed a significant percentage of minerals, proteins, carbohydrates and vitamin $\mathrm{C}$ in all the leaf extracts. Phytochemical screening displayed Ceylon Spinach, Pumpkin and Mustard leaves to be rich sources of polyphenols (106.6, 76.24 and $89.86 \mathrm{mg} / 100 \mathrm{~g})$ and alkaloids $(12.8 \%, 13.2 \%$ and $16.8 \%)$ respectively. Furthermore, these edible leaves could effectively scavenge 2, 2-diphenyl-1-picryl-hydrazyl (DPPH) and hydrogen peroxide $\left(\mathrm{H}_{2} \mathrm{O}_{2}\right)$ free radicals with Mustard leaves showing the greatest efficiency, hence portraying antioxidant properties. Ceylon Spinach leaves depicted the highest reducing power compared to the other samples. Additionally, the edible leaf extracts were shown to possess anti-bacterial abilities with Mustard leaves displaying the strongest inhibition against growth of both Gram positive (ZOI $18.5 \mathrm{~mm}$ ) and negative bacteria (ZOI $25.5 \mathrm{~mm}$ ). Interestingly, the selected samples could also elevate the growth of probiotic Lactobacillus acidophilus in vitro thereby confirming their prebiotic potential. Therefore, inclusion of these edible leaves in the diet may promote good health owing to their nutritional and therapeutic benefits.
\end{abstract}

Keywords: Affordability; Antioxidant; Edible; Phyto-constituents; Tradition.

(C) 2020 JSR Publications. ISSN: 2070-0237 (Print); 2070-0245 (Online). All rights reserved. doi: http://dx.doi.org/10.3329/jsr.v12i4.45110

J. Sci. Res. 12 (4), 621-632 (2020)

\section{Introduction}

Plant food serves as a major source of nutrients for majority of the world's population. Edible leaves are those plants whose leaves or aerial parts have been integrated in a community's culture for use as food over a long span of time. These vegetables are recommended due to their relatively high nutritional value. The hemi-cellulose, cellulose and pectin present in them impart the desired texture and firmness. Leaves are valuable sources of essential components that are generally in short supply in the daily diet. Moreover, being low in fat and energy density, they are also popular for weight management [1]. Green edible leaves are good and one of the most economical sources of proteins. Furthermore, these leaves are rich in minerals including iron, calcium,

${ }^{*}$ Corresponding author: $\underline{\text { deb_anindita@yahoo.com }}$ 
potassium, zinc, sodium and copper. Moreover, they are popular for their vitamin contents, especially vitamin B complex, A, C and K [2]. Edible leaves have been known to contain significant fractions of soluble dietary fibers that reduce incidences of cardiovascular disorders, constipation, diabetes, diverticulosis and even obesity [3].

Withstanding their value as food, edible leaves also serve as powerful sources of medicine owing to their ability to synthesize a variety of chemical compounds that play a major role in health care as therapeutic remedies. Traditionally, people have used leafbased preparations for the treatment of infectious diseases. Biochemical studies have demonstrated a positive correlation between the intake of leafy vegetables and reduced rates of degenerative diseases [4]. Secondary metabolites and phytochemicals including carotenoids, flavonoids, phenols, tannins and anthocyanins have been shown to protect against chronic and infectious human disorders [5,6]. Furthermore, the vitamins, carotenoids and phenolic compounds present in these leaves have been found to portray antioxidant potential, thereby aiding towards wellbeing [7]. Additionally, edible leaves have been associated with potent anti-microbial action due to the presence of phenolic compounds, tannins and flavonoids [8]. Hence, regular consumption of edible leaves could promote improved health. These are also appreciable sources of polysaccharides, which when fermented in the intestine helps to stimulate the growth of selective colonic microflora thereby providing a beneficial effect to the human body [9].

Poverty, food insecurity, loss of biological and cultural diversity as well as environmental degradation are some of the major worldwide challenges [10]. Edible food sources including edible leaves can help to overcome the above. Diversification in production and consumption pattern of leafy vegetables could not only contribute towards improved health and nutrition but also reinforce ecological sustainability [11]. Moreover, functional components present in them may provide medicinal remedies. Edible leaves are one of the most economical forms of vegetable possessing multiple benefits. The present study focuses on the nutritional and functional properties of selected edible leaves. Cucurbita moschata (Pumpkin leaves), Baselle alba (Ceylon Spinach leaves)and Brassica juncea (Mustard leaves)were used in this study. The samples were selected based on low cost, ease of harvest, availability as well as consumption within the local population. Mustard leaves have been popular as potent nutritional and mineral sources [12]. Ceylon spinach and Pumpkin leaves are also common traditional vegetables that are preferred due to their ready availability and potential benefits [13]. Interestingly, previous studies have implicated Mustard leaves and Spinach as attractive choices for food security, especially in developing countries [14,15]. Moreover, leaves of Pumpkin and Ceylon Spinach have been indicated to deliver pharmacological advantages [16]. Hence, the selected leaves were comparatively analyzed for their complete proximate composition and functional attributes in order to ascertain their usefulness towards nutritional security as well as pharmacological outcomes. The current investigation attempts to add on to the earlier researches carried out on the biochemical parameters of edible leaves and to bridge the limitation in scientific knowledge regarding their different properties. Determination of 
the above may empower the population with beneficial food options, thereby enhancing overall health and wellbeing.

\section{Materials and Methods}

\subsection{Sample selection and preparation of extract}

Fresh samples of Cucurbita moschata (Pumpkin leaves), Baselle alba (Ceylon Spinach leaves) and Brassica juncea(Mustard leaves)used in this study were purchased from local vegetable markets situated in North Kolkata. The freshly collected leaves were separated from the stem followed by washing with distilled water to remove sand and other impurities. These leaves were air-dried at room temperature to remove the surface water. The dried leaves were then ground into a fine powder, sieved and stored in zip-lock sterile polythene bags. Leaf extracts were prepared by soaking $15 \mathrm{~g}$ of powdered sample in distilled water or ethanol followed by filtration. The extracts were stored in sterilized airtight containers at $4{ }^{\circ} \mathrm{C}$.

\subsection{Proximate analysis}

The moisture, ash, lipid, crude fiber, protein and carbohydrate contents were determined by methods recommended by the Association of Official Analytical Chemists (AOAC) [17]. Briefly, the moisture content of the samples was determined by oven drying $5 \mathrm{~g}$ of the selected leaves at $150{ }^{\circ} \mathrm{C}$ to a constant weight. Percentage of ash was obtained by igniting the powdered sample in a muffle furnace at $600{ }^{\circ} \mathrm{C}$. Protein and total carbohydrate concentrations were estimated by using the Biuret and Anthrone methods respectively. Semi-continuous Soxhlet extraction was used to calculate the proportion crude lipids in the edible leaves. Crude fiber content was determined by acid-base digestion method using $1.25 \% \mathrm{H}_{2} \mathrm{SO}_{4}$ and $1.25 \% \mathrm{NaOH}$ solutions respectively.

\subsection{In vitro phytochemical analysis}

\subsubsection{Qualitative estimation}

Qualitative analysis for the screening and identification of bioactive chemical constituents present in Pumpkin leaves, Mustard leaves and Ceylon Spinach leaves was carried out with the ethanolic extracts using the standard procedure as described by Santhi, et al. [18]. The samples were qualitatively estimated to determine the presence of alkaloids, phenols, flavonoids and saponins.

\subsubsection{Quantitative estimation of total polyphenols}

Total phenolic content of raw samples was determined by using the Folin-Ciocalteau micro method. Calibration curve was prepared by using different concentration of the gallic acid solution. $0.5 \mathrm{~mL}$ of the standard or sample solution was mixed with $0.5 \mathrm{~mL}$ of $10 \%$ Folin-Ciocalteu reagent followed by $4 \mathrm{~mL}$ of anhydrous sodium carbonate. The test 
tubes incubated at $40{ }^{\circ} \mathrm{C}$ for $30 \mathrm{~min}$. Absorbance was measured at $765 \mathrm{~nm}$ using UV VIS spectrophotometer (Hitachi UV-VIS Spectrophotometer U2900, India).

\subsubsection{Quantitative estimation of alkaloids}

$5 \mathrm{~g}$ of the powdered samples were dissolved in $20 \mathrm{~mL}$ of acetic acid (20\%). It was allowed to stand for 4-6 h. After that, it was filtered and the filtrate was kept on a hot water bath for evaporating it to one quarter of its original volume. The alkaloids were precipitated by adding concentrated ammonium hydroxide drop by drop or until precipitation was completed. The precipitates were collected by filtration through Whatman No. 1 filter paper. These residues were allowed to dry in an oven followed by weighing. The percentage of alkaloid content was calculated with respect to the original weight of the sample.

\subsection{In vitro antioxidant quantification}

\subsubsection{DPPH radical scavenging assay}

The free radical scavenging ability of the leaf extracts against 2,2-diphenyl-1-picrylhydrazyl (DPPH) was evaluated according to the procedure described by Izuegbuna et al. [19] with a slight modification. Ascorbic acid solution $(0.2-1.0 \mathrm{mg} / \mathrm{mL})$ was taken as the standard. The DPPH reaction mixture was made by mixing ethanolic solution of DPPH with standard or sample in the ratio 1:1. The test tubes were incubated for $30 \mathrm{~min}$ in dark followed by measurement of absorbance at $517 \mathrm{~nm}$. Percentage of inhibition (DPPH inhibition \%) was calculated using the given formula ([AC - AS] / AC) $\times 100$; where AC is the absorbance of control and AS is the absorbance of the sample or standard.

\subsubsection{Reducing power property}

The leaf extracts were assessed for the reducing power using the method used by Alimi et al. [20]. $1 \mathrm{~mL}$ of distilled water was added to different concentrations of the leaf extracts followed by mixing with $0.2 \mathrm{M}$ phosphate buffer and $1 \%$ potassium ferrocyanide respectively. The mixture was incubated at $50{ }^{\circ} \mathrm{C}$ for $20 \mathrm{~min}$ before the addition of trichloroacetic acid. The resulting mixture was centrifuged for $10 \mathrm{~min}$. The supernatant was mixed with an equal amount of distilled water and $0.1 \% \mathrm{FeCl}_{3}$. Absorbance was measured at $700 \mathrm{~nm}$ using UV VIS spectrophotometer.

\subsubsection{Hydrogen peroxide scavenging activity}

Hydrogen peroxide scavenging activity was assessed by the method described by Oboh $e t$ al. [21]. Freshly prepared leaf extracts or standards (Vitamin C) were added to a preprepared reaction mixture containing $20 \mathrm{mM}$ deoxyribose, $0.1 \mathrm{M}$ phosphate buffer $(\mathrm{pH}$ 7.4) and $500 \mathrm{mM} \mathrm{FeSO}$. The volume was made up to $200 \mathrm{~mL}$ with distilled water. The reaction was initiated at $37{ }^{\circ} \mathrm{C}$ for $30 \mathrm{~min}$, after which it was terminated by adding $50 \mathrm{~mL}$ of trichloroacetic acid followed by $50 \mathrm{~mL}$ of thiobarbituric acid solution. The mixture was incubated in boiling water followed by measurement of absorbance at $532 \mathrm{~nm}$. 


\subsection{In vitro prebiotic potential}

De Man, Rogosa and Sharpe (MRS) broth was used to check the in vitro prebiotic potential of the leaf extracts. The broth was cultured with Lactobacillus acidophilus (MTCC 10307) followed by incubated at $37{ }^{\circ} \mathrm{C}$ for $24 \mathrm{~h}$ under anaerobic conditions. The assay was done as per the protocol reported by Yadav et al. but with a slight modification [22]. MRS medium with $1 \%$ sub cultured broth and $2 \%$ leaf extract was incubated in a Nephelometer at $37{ }^{\circ} \mathrm{C}$. The growth was determined by measuring the Optical Density at $700 \mathrm{~nm}$ using a spectrophotometer every $1 \mathrm{~h}$ for a period of $48 \mathrm{~h}$.

\subsection{Anti-microbial potential}

Anti-bacterial activities of leaf samples were evaluated using well diffusion method on nutrient agar against Gram positive Bacillus subtilis (MTCC 1305) and Gram negative Escherichia coli (MTCC 40). Antimicrobial property was determined by using a protocol reported by Shahriar et al. [23] and the zone of inhibition (ZOI) was calculated against ethanol (negative control) to check the effectiveness of the extract. Chloramphenicol $(20 \mu \mathrm{g} / \mathrm{mL})$ was used as the positive control.

\subsection{Statistical analysis}

Data was analyzed using Microsoft excel data analysis software (version 2007). Results were expressed as mean \pm standard error of mean of $\mathrm{N} \geq 3$ individual experiments. $\mathrm{P}$ values were estimated using the Graph Pad software (California, USA). Only P value $<0.05$ was considered statistically significant.

\section{Results and Discussion}

\subsection{Proximate composition}

Table 1. Proximate composition of the leaf samples.

\begin{tabular}{|c|c|c|c|}
\hline \multirow[b]{2}{*}{ Parameter } & \multicolumn{3}{|c|}{ Concentration (\% Dry weight) ${ }^{\mathrm{ab}}$} \\
\hline & $\begin{array}{c}\text { Cucurbita moschata } \\
\text { (Pumpkin leaves) }\end{array}$ & $\begin{array}{l}\text { Baselle alba (Ceylon } \\
\text { Spinach leaves) }\end{array}$ & $\begin{array}{l}\text { Brassica juncea } \\
\text { (Mustard leaves) }\end{array}$ \\
\hline Moisture $^{b}$ & $61.8^{* *}$ & $92.9^{*}$ & $72.5^{*}$ \\
\hline Ash & $27.2^{*}$ & $51.7^{* *}$ & $32^{* *}$ \\
\hline Total Carbohydrates & $1.77^{* * * *}$ & $2.17^{* *}$ & $2.58^{* * * *}$ \\
\hline Protein & $3.25^{* * *}$ & $5.64^{* * * *}$ & $4.11^{* * *}$ \\
\hline Lipid & $1.8^{* * *}$ & $1.2^{*}$ & $4.1^{*}$ \\
\hline Crude Fiber & $19.5^{* *}$ & $21^{*}$ & $15^{*}$ \\
\hline
\end{tabular}

All three edible leaf samples showed significantly high moisture content with Ceylon spinach exhibiting the highest percentage $(92.9 \%)$ as depicted in Table 1 . The moisture content is dependent on the leaf variety and influences shelf life. Therefore, the leaves 
analyzed were not recommended for long-term storage owing to their high moisture levels. Ceylon Spinach, Mustard leaves and Pumpkin leaves displayed an ash content of $51.75 \%, 32 \%$ and $27.2 \%$ individually thereby qualifying as good sources of minerals. Furthermore, all samples showed the presence of carbohydrates and proteins with Mustard leaves and Ceylon spinach possessing the highest amounts of the two nutrients compared to the other samples. Indeed Mustard leaves contained $2.58 \%$ carbohydrates and $4.11 \%$ proteins whereas Ceylon Spinach leaves showed $2.17 \%$ and $5.64 \%$ of carbohydrates and proteins respectively. On the contrary, Pumpkin leaves displayed a carbohydrate content of $1.77 \%$ in addition to $3.25 \%$ proteins. Edible leaves being economical can be used either alone or in combination to increase the Biological Value of food and alleviate the symptoms of Protein Energy Malnutrition (PEM). Interestingly, the leaf samples displayed a low fat content as indicated in Table 1 thereby being suitable for fat restricted diets followed by several people, especially those suffering from obesity and other metabolic disorders. However, Mustard leaves were seen to contain $4.1 \%$ fat. All samples were observed to have appreciable amounts of crude fiber hence proving to be beneficial for improvement of gastrointestinal function. Moreover, fiber content also indicated the probability of a prebiotic potential in the samples. Therefore, the selected edible leaves qualified as good sources of total carbohydrates, proteins, minerals and fibers along with possessing a low fat percentage thereby potentiating as an attractive nutritive food.

\subsection{Antioxidant properties}

Antioxidant properties of leaf samples were investigated in vitro by DPPH assay. The inhibition of the free radicals was expressed as percent (\%) inhibition. All extracts exhibited effective antioxidant potential. Indeed Mustard, Ceylon Spinach, and Pumpkin leaves were seen to possess $45.3 \pm 0.57 \%, 44.5 \pm 0.86 \%$ and $40 \pm 0.51 \%$ radical scavenging potential individually (Fig. 1A). Reducing power assay is another convenient and rapid screening method for measurement of antioxidant activity. Although all samples displayed significant reducing power abilities, Ceylon Spinach leaves displayed the greatest reducing potential followed by Mustard and Pumpkin leaves (Fig. 1B). Additionally, the Hydrogen Peroxide $\left(\mathrm{H}_{2} \mathrm{O}_{2}\right)$ foraging potential of the extracts was evaluated. Results depicted in Fig. 1C reveal that all extracts possessed the capability to scavenge $\mathrm{H}_{2} \mathrm{O}_{2}$ with the highest being Mustard leaves $(69.99 \pm 0.58 \mu \mathrm{g} / 100 \mathrm{~mL}$ leaf extract) compared to Ceylon Spinach $(55.79 \pm 0.86 \mu \mathrm{g} / 100 \mathrm{~mL})$ and Pumpkin leaves $(50.69 \pm 0.50 \mu \mathrm{g} / 100 \mathrm{~mL})$. The leaves were further analyzed for Vitamin $\mathrm{C}$ content that imparts several health benefits including protection against free radicals. Results of figure 1D portrayed that all the three leaf extracts contained effective concentrations of Vitamin $\mathrm{C}$ thereby further confirming their antioxidant capacities. However, the content of this vitamin was found to be highest in Mustard leaves $(30.88 \pm 1.36 \mathrm{mg} / 50 \mathrm{~g})$ followed by leaves of Pumpkin and Ceylon Spinach. Therefore, all the edible samples displayed comparable antioxidant capacities. However, the efficiency of Mustard leaves towards prevention of free radical mediated damage was slightly higher as compared to the other two samples owing to its greater DPPH and $\mathrm{H}_{2} \mathrm{O}_{2}$ scavenging capabilities as well as vitamin $\mathrm{C}$ concentration. 
Therefore, consumption of these edible leaves may offer protection against Reactive Oxygen Species (ROS) thereby protecting against oxidative stress mediated disorders. The antioxidant activity of the edible samples may be attributed to the presence of some phytochemicals like flavonoids, alkaloids, phenolic compounds as well as vitamins including Vitamin C. Hence, dietary incorporation of these leaves may help protect the body against free radicals induced damages due to their potent antioxidant properties.
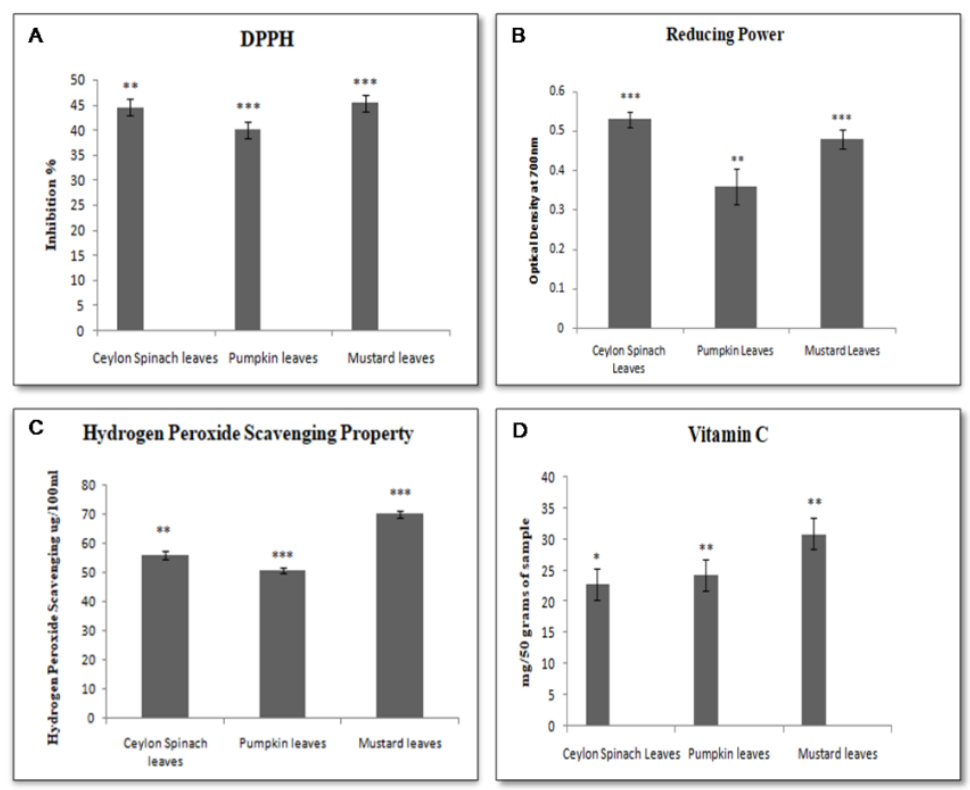

Fig. 1. Antioxidant potential of Leaves. (A) DPPH radical scavenging activity, (B) Reducing power, (C) Hydrogen peroxide scavenging property, (D) Vitamin C content.

\subsection{Phytochemical constitution}

Table 2. Qualitative estimation of phytochemicals in the edible leaves.

\begin{tabular}{lcccc}
\hline Sample & Alkaloid & Polyphenol & Flavonoid & Saponin \\
\hline Cucurbita moschata & +++ & +++ & ++ & - \\
Baselle alba & +++ & +++ & ++ & - \\
Brassica juncea & +++ & +++ & ++ & - \\
\hline$+++\&$ ++ denote very high and moderately high levels respectively & &
\end{tabular}

Phytoconstituents are bioactive chemicals that are of plant origin. Table 2 represents the results of qualitative phytochemical screening of the three edible leaves. All leaf extracts were demonstrated to contain appreciable amounts of alkaloids and polyphenols followed by flavonoids. However, none of the samples showed the presence of saponins. Since the above leaves indicated the presence of high amounts of alkaloids and polyphenols, these components were further quantitatively estimated. Alkaloid content of the leaves is 
represented in Fig. 2A. The total alkaloid content present in raw Mustard leaf sample was found to be highest $(16.93 \pm 0.46 \%)$ compared to Pumpkin leaves $(13.16 \pm 0.20 \%)$ and Ceylon Spinach leaves $(12.76 \pm 0.12 \%)$. Alkaloids are naturally occurring chemical compounds derived from plants that have been reported to exhibit anti-depressant, antibacterial, anti-proliferation, anti-viral, insecticidal, and anti-metastatic effects in the body. Extracts of Ceylon Spinach leaves, Mustard leaves and Pumpkin leaves showed $106.6 \mathrm{mg} / 100 \mathrm{~g}, 89.86 \mathrm{mg} / 100 \mathrm{~g}$ and $76.26 \mathrm{mg} / 100 \mathrm{~g}$ of polyphenols respectively (Fig. 2B). The presence of appreciable quantities of polyphenols and alkaloids may also be contributing to the free radical scavenging activity of the edible samples as portrayed in Fig. 1. Therefore, all the three samples were found to contain significant amounts of the above phytochemicals. However, Mustard leaves and Ceylon Spinach leaves portrayed highest concentrations of alkaloids and polyphenols respectively compared to the other samples. The presence of these compounds may be responsible for several functional benefits including antioxidant, anti-microbial and prebiotic actions.
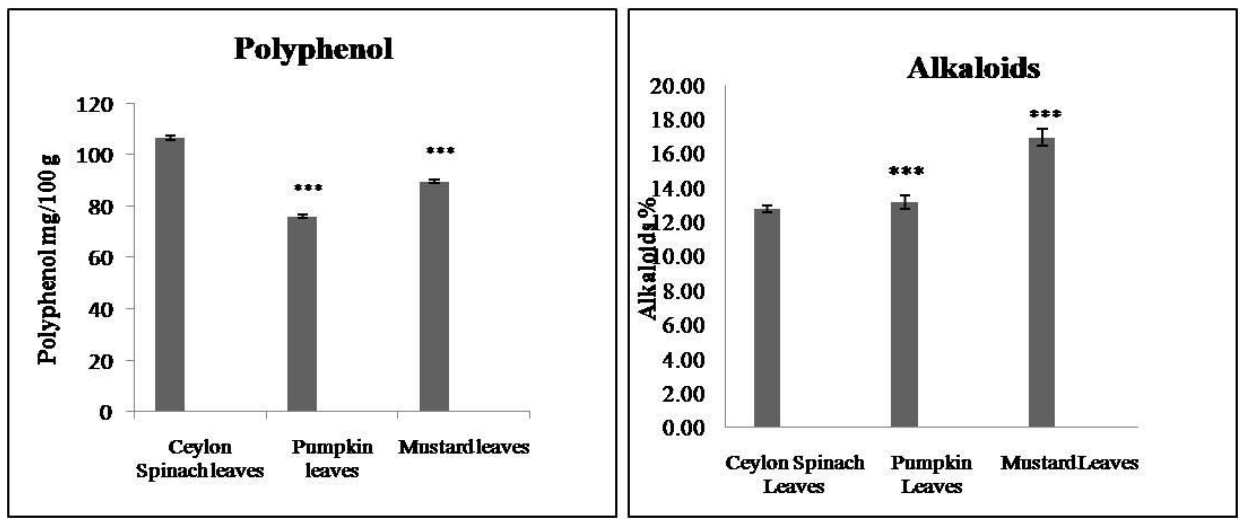

Fig. 2. Quantitative estimation of phytochemicals in the edible leaves.

\subsection{In vitro prebiotic potential}

Since the selected edible leaves were observed to contain significant amounts of polysaccharides including fiber as well as phytochemicals, they were further analyzed for their prebiotic potential. Prebiotic activity was measured by monitoring the ability of the extracts to increase the proliferation of probiotic Lactobacillus acidophilus by fermentation of the prebiotic polysaccharides and utilization of phytoconstituents by the bacteria. Indeed the color of the media showed a transition from colourless to cloudy and finally deep yellow with the addition of the leaf extracts. All leaf extracts accelerated the growth of Lactobacillus with an increasing time interval post $20 \mathrm{~h}$ compared to the control. The growth was monitored for duration of $48 \mathrm{~h}$. Increased growth was observed with Mustard, Ceylon Spinach and Pumpkin leaves as portrayed by their growth maxima represented by Optical Densities (OD) of $0.18,0.17$ and 0.16 respectively during the $48 \mathrm{~h}$ interval (Fig. 3). The log phase of the probiotic bacteria incubated with Mustard leaves 
showed tremendous growth as displayed by transition of OD from 0.1 to 0.18 during the time interval of 24 to $48 \mathrm{~h}$. In contrast, the control had a slower growth depicted by a change in OD from 0.07 to 0.11 in the same time duration, beyond which it entered the stationary phase. Ceylon Spinach leaves also showed a good prebiotic potential. The log phase of Lactobacillus growing in the presence of Ceylon Spinach leaves showed an increase in OD from 0.08 to 0.17 before entering the stationary phase. Pumpkin Leaves depicted the lowest prebiotic potential compared to the other two samples, but higher than control (Fig. 3). Interestingly, although the growth cycle of L. acidophilus was observed to enter the stationary phase when inoculated with extracts of Pumpkin and Ceylon Spinach leaves, Mustard leaves were depicted to continuously accelerate the proliferation of the cells thereby expanding the logarithmic phase of the microorganism. However, all the sample extracts were found to significantly elevate the growth of the probiotic microorganism with respect to the control during the above time span. This effect may be attributed to the presence of soluble dietary fibers, polyphenols and alkaloids in the extracts. Hence, all leaf samples displayed a promising prebiotic potential with the highest activity shown by Mustard leaves. Prebiotics are known to confer therapeutic advantages apart from improving the overall health. Hence, inclusion of these leaves in the diet may help in the modulation of the gut micro-flora thereby aiding towards improved wellbeing.

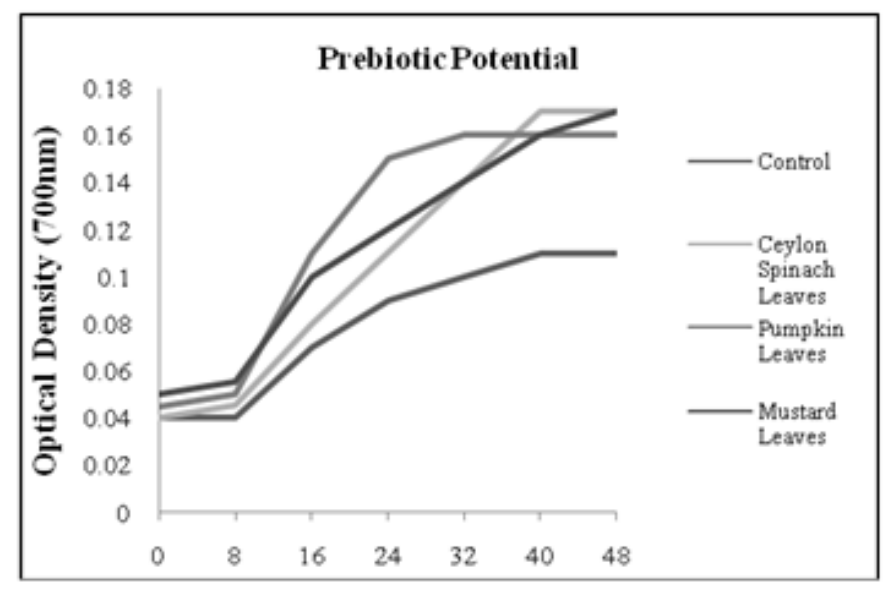

Fig. 3. Prebiotic potential of the edible leaves.

\subsection{Anti-bacterial property}

Since the edible leaves displayed the presence of phytochemicals especially polyphenols and alkaloids, the ability of the same to inhibit pathogenic growth was evaluated. The anti-bacterial activity of the leaf extracts against pathogenic Gram-negative E. coli and Gram-positive B. subtilis was experimented. Ethanol and chloramphenicol were taken as the negative and positive controls respectively. Mustard Leaves were highly effective in inhibiting the growth of both the pathogenic bacteria compared to Ceylon Spinach and Pumpkin leaves as depicted by a ZOI of $25.5 \mathrm{~mm}$ and $18.5 \mathrm{~mm}$ respectively (Fig. 4). 
Furthermore, Ceylon Spinach leaves generated a ZOI of $14.5 \mathrm{~mm}$ and $9.0 \mathrm{~mm}$ against $E$. coli and B. subtilis independently. Pumpkin leaves portrayed the lowest anti-microbial property against both the pathogens amongst all the selected samples (Fig. 4). Interestingly, all the three edible extracts displayed a higher anti-bacterial potential against $E$. coli compared to $B$. subtilis that may be due to the differences in the cell wall constituency of the strains. Therefore, consumption of these leaves would prove beneficial in improving the nutritional status along with bestowing therapeutic benefits including protection against pathogenic microorganisms.

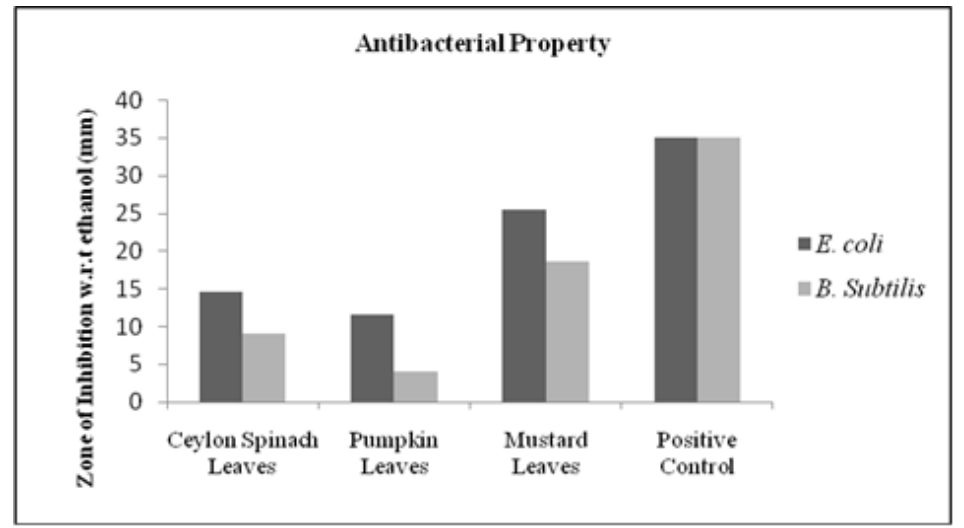

Fig. 4. Anti-bacterial property of the edible leaves.

\section{Conclusion}

Leaves are multi-purpose parts of the plant possessing high nutritional values and wide medicinal applications. They also contain secondary metabolites conferring functional benefits in a human system. Based on the nutritional and functional evaluation of the selected edible leaves, it can be summarized that these samples are significant sources of macronutrients, micronutrients as well as non-nutritive compounds including phytochemicals that exhibit beneficial properties. Mustard leaves were found to perform best in terms of the above parameters. These leaf extracts displayed the strongest DPPH and $\mathrm{H}_{2} \mathrm{O}_{2}$ scavenging capabilities (45.3\% and $69.99 \mu \mathrm{g} / 100 \mathrm{~mL}$ respectively) in addition to elevated concentrations of Vitamin C $(30.88 \mathrm{mg} / 50 \mathrm{~g})$ and alkaloids (16.93\%) amongst all the studied samples. Moreover, they also showed the highest prebiotic and antibacterial potential as observed in the results of the analysis. Ceylon Spinach leaves can also be considered as good sources of nutrients and phytochemicals. These edible samples were observed to contain appreciable contents of carbohydrates, proteins, lipids, crude fiber and minerals. Furthermore, these leaves possessed the greatest reducing power $\left(\mathrm{OD}_{700} 0.53\right)$ as well as polyphenol content $(106.6 \mathrm{mg} / 100 \mathrm{~g})$ compared to the others. The free radical foraging abilities along with prebiotic and anti-microbial potential were also significantly associated with these samples although their levels were lower than Mustard leaves. Additionally, Pumpkin leaves were found to be good nutritional and functional 
sources though their efficiencies were found to be reduced in comparison to either Mustard or Ceylon Spinach leaves. The polyphenol and alkaloid contents observed in the three edible leaves may be responsible for the observed antioxidant, probiotic and antibacterial properties. Interestingly, previous studies have indeed reported long-term consumption of polyphenol rich food to protect against coronary heart diseases, cancers, diabetes, pancreatitis, osteoporosis, lung damage, gastrointestinal disorders as well as neurodegenerative diseases. Vitamin $\mathrm{C}$ has also been associated with improved immune function and protection against pathogens. Besides, dietary fibers, polyphenols and alkaloids have been associated with enhanced gut health that may hence be responsible for the detected prebiotic potential of the edible samples. Therefore, consumption of these edible leaves may not only bestow nutritional empowerment but also therapeutic benefits. These edible samples are attractive commodities owing to their low cost and ready availabilities. Moreover, leaves being natural contain components possessing low toxicity compared to synthetic drugs available in the market. Hence, awareness regarding the nutritional and functional properties of these under-utilized leaves may aid towards nutritional and food security in addition to generating novel therapeutic avenues. Thus, knowledge of the above properties may help the population in adapting an improved food choice.

\section{References}

1. F. A. Soeliman and L. Azadbakht, J. Res. Med. Sci. 19, 268 (2014).

2. M. Edelman and M. Colt, Frontiers Chem. 4, 153 (2016). https://doi.org/10.3389/fchem.2016.00032

3. D. Dhingra, M. Michael, H. Rajput, and R. T. Patil, J. Food Sci. Technol. 49, 255 (2012). https://doi.org/10.1007/s13197-011-0365-5

4. R. L. Pollock, JRSM Cardiovascular Diseases 5, 221 (2016). https://doi.org/10.1177/2048004016661435

5. M. Ebadi, Pharmacodynamic Basis of Herbal Medicine (CRC Press, US, 2007). https://doi.org/10.1201/9781420006452

6. K. O. Soetan, Afric. J. Biotechnol. 7, 4713 (2008).

7. S. T. Ho, Y. T. Tung, Y. L. Chen, Y. Y. Zhao, M. J. Chung, and J. H. Wu, Evid. Based Complement. Alt. Med. 14, 245 (2012).

8. G. Singh and P. Kumar, Int. J. Appl. Basic Med. Res. 3, 111 (2013). https://doi.org/10.4103/2229-516X.117082

9. T. S. Zaporozhets, N. N. Besednova, T. A. Kuznetsova, T. N. Zvyagintseva, I. D. Makarenkova, S. P. Kryzhanovsky, and V. G. Melnikov, Russ. J. Marine Biol. 40, 1 (2014). https://doi.org/10.1134/S1063074014010106

10. I. Moreno-Calles, A. Casas, A. D. Rivero-Romero, Y. A. Romero-Bautista, S. Rangel-Landa, R. A. Fisher Ortíz, F. Alvarado-Ramos, M. Vallejo-Ramos, and D. Santos-Fita, J. Ethnobiol. Ethnomed. 12, 2 (2016). https://doi.org/10.1186/s13002-016-0127-6

11. M. Leonti, Genet. Resour. Crop Evolut. 59, 1295 (2012). https://doi.org/10.1007/s10722-0129894-7

12. A. M. S. Lima, L. O. D. Santos, J. M. David, and S. M. C. Ferreira, Food Chem. 273, 172 (2019). https://doi.org/10.1016/i.foodchem.2017.12.042

13. J. N. Lekunze, J. Human Ecol. 48, 61 (2017). https://doi.org/10.1080/09709274.2014.11906775 
14. A. Singh, P. K. Dubey, R. ChaurasiYa, N. Mathur, G. Kumar, S. Bharati, and P. C. Abhilash, Energy, Ecol. Environ. 3, 195 (2018). https://doi.org/10.1007/s40974-018-0091-1

15. P. Dube, W. J. M. Heijman, R. Ihle, and J. Ocsieng, Establishing Food Security and Alternatives to International Trade in Emerging Economies (IGI Global, USA, 2018).

16. A. K. Tiwari, Pharmacognosy Magazine 10, S207 (2014). https://doi.org/10.4103/0973-1296.133211

17. G. W. Latimer, Official Methods of Analysis of AOAC International (Association of Official Analytical Chemists, USA, 2019).

18. K. Santhi and R. Sengottuvel, Int. J. Current Microbiol. Appl. Sci. 5, 633 (2016). https://doi.org/10.20546/ijcmas.2016.501.064

19. O. Izuegbuna, G. Otunola, and G. Bradley, Pharmacognosy 11, 237 (2018). https://doi.org/10.5530/pj.2019.11.37

20. A. Alimi and A. O. T. Ashafa, Asian Pacific J. Tropical Biomed. 7, 765 (2017). https://doi.org/10.1016/j.apjtb.2017.08.004

21. G. Oboh, R. L. Puntel, and J. B. T. Rocha, Food Chem. 102, 178 (2007). https://doi.org/10.1016/j.foodchem.2006.05.048

22. S. A. Yadav, S. S. Gite, V. B. Lanjekar, S. S. Nilegaonkar, and V. V. Agte, Int. J. Current Microbiol. Appl. Sci. 3, 137 (2014).

23. M. Shahriar, M. A. Bhuiyan, and M. S. Rana, J. Sci. Res. 10, 195 (2018).

https://doi.org/10.3329/jsr.v10i2.35410 